\title{
Machine Learning Methods to Classify Mushrooms for Edibility-A Review
}

\author{
Rakesh Kumar $\mathrm{Y}^{1} \mid$ Dr. V. Chandrasekhar ${ }^{2}$ \\ ${ }^{1}$ Dept. of Electronics and Communication Engineering, Research Scholar, Osmania University, Hyderabad, India. \\ ${ }^{2}$ Dept. of Electronics and Communication Engineering Former principal \& Professor, MVSR Engineering College, \\ Hyderabad, India
}

\section{To Cite this Article}

Rakesh Kumar Y and Dr. V. Chandrasekhar, "Machine Learning Methods to Classify Mushrooms for Edibility-A Review", International Journal for Modern Trends in Science and Technology, 6(9): 54-58, 2020.

\section{Article Info}

Received on 08-August-2020, Revised on 18-August-2020, Accepted on 27-August-2020, Published on 01-September-2020.

\section{ABSTRACT}

There are thousands of species of Mushrooms in the world; they are edible and non-edible being poisonous. It is difficult for non-expertise person to Identify poisonous and edible mushroom of all the species manually. So a computer aided system with software or algorithm is required to classify poisonous and nonpoisonous mushrooms. In this paper a literature review is presented on classification of poisonous and nonpoisonous mushrooms. Most of the research works to classify the type of mushroom have applied, machine learning techniques like Naïve Bayes, K-Neural Network, Support vector Machine(SVM), Artificial Neural Network(ANN), Decision Tree techniques. In this literature review, a summary and comparisons of all different techniques of mushroom classification in terms of its performance parameters, merits and demerits faced during the classification of mushrooms using machine learning techniques.

KEYWORDS: Data Mining Techniques, Mushroom Edibility Classification, Machine Learning Techniques, Image Processing Methods, UCI Machine Learning Repository.

\section{INTRODUCTION}

Varying degrees of protein and fiber are available in all kinds of edible mushrooms. Mushrooms contain vitamin B element called selenium, a powerful anti-oxidant which supports immune system. The research work on mushrooms is increasing day by day because of its health benefits and different medicinal properties. These commercially available mushrooms like button, milky, oyster etc., only are edible and it has become a great source of business for small farmers. Mushroom hunting, from the term we could say that collecting mushrooms in the wild for food is a well practice in most of the places. Therefore, the common safety advice to consume mushrooms is that only truly recognized mushrooms should be eaten. At this point we may not be able to identify edible and non-edible mushrooms.

Developing a computer aided system by training the system with various machine learning algorithms depending on the accuracy helps many of them to classify mushrooms and protect them from consuming poisonous mushrooms. Unknowingly, if humans consume toxic mushrooms may lead to allergic reactions, vomiting and sometimes even death. Detecting poisonous mushrooms with naked eyes is always a trivial task for human. So classifying edible from poisonous mushrooms is a great need and demand to save lives of mushroom hunters.

This paper deals with comprehensive overview of recent research in classification of edible and non-edible mushrooms. The remaining part of the paper is organized as: Section II provides the literature review on edible mushroom 
classification;comparative analysis on different classification methods is presented in section III; Finally, Section IV concludes the paper.

\section{Classification of Edibility Mushroom}

S.K. Verma, M Dutta [1] focused on evaluating the performance of different classification methods like Artificial Neural Networks (ANN), Adaptive Nuero Fuzzy inference system (ANFIS) and Naïve Bayes on mushroom data sets collected from UCI Machine Learning Repository. Data set considered consists of 8124 instances, 22 attributes and 2 possible classes of edible and non-edible. The parameters used to analyze the performance of ANN, ANFIS and Naïve bayes algorithm are incorrectly classified instances (ICCI), correctly classified instances (CCI), MAE, Kappa statistic. It is observed from the results that ANFIS is performing better than ANN and Naïve Bayes. It is also observed that Accuracy is increasing as training set is increased.

Nusrat Jahan Pink, S. M.Mohidaul Islam, Rafia Sharmin Alice, [2] used ensemble Techniques developed by combining different classifiers to classify the edible and poisonous mushrooms. Naïve Bayes and dissimilarity measure are used for bagging; Adaboost is used for boosting and decision Tree is used for random forests. Mushroom dataset was taken from UCI machine learning repository and dataset consists of edible and non-edible of 8124 instances and 22 attributes with 2 possible class levels. These 22 tributes are Odour, cap-surface, cap-shape, cap-color, bruises, gill-size, gill-shape, gill-attachment, stalk-root, stalk-shape, stalk-color-below-ring, stalk-color-above-ring, stalk-surface-above-ring, and stalk-surface-below-ring, habitat, population, ring-type, veil-color, veil-type, ring type, ringnumber, spore-print-color. Five base models of each ensemble method using five feature sets are developed by selecting the most significant feature set. To test the performance, accuracy is considered for both randomly selected feature set and fixed feature set are considered for ensemble methods. The better performance is obtained by fixed feature set based models compared to randomly selected feature set based models. The accuracy is found to be high for random forest and dissimilarity measure -based bagging, but random forest is faster than the dissimilarity measure based bagging method.

Yasemin Rukiye Erhan, Humar Kahramanli Ornek [3] to classify edible and non edible mushrooms an image processing technique thresholding segmentation method is used to separate object and background. Then dilation and erosion is used to highlight or magnify the objects in binary images. Then classification techniques K-NN and Naïve Bayes were used to classify the segmented image. Data set of 25 mushroom types were grown naturally and collected from selcuk university campus, out of 25 mushroom types 8 were edible and 17 were non-edible. Experiment was carried out in Microsoft visual studio 2012 software. After analyzing results it was found that Accuracy of Naïve Bayes algorithm is $96 \%$ and $80 \%$ is achieved by K-NN. Naïve Bayes performs better than K-NN algorithm for small amount of data sets.

Eyad Sameh Alkronz et.al [4] developed a model by using Artificial Neural Network (ANN) to detect edibility of mushrooms fed as input to the model. A multi layer ANN model is developed with one input layer, three hidden layers and one output layer was used to train and test the mushroom data set. The mushrooms represented data set was collected from UCI machine learning repository and dataset consists of edible and non-edible of 8124 samples (training samples are 5724 and test samples are 2400) and 22 attributes with 2 possible class levels. The network structure is developed by Just NN software and trained for 161501 epochs. After trial and error process, finally states that the best results were obtained by considering 22 attributes as 22 input neurons, 3 hidden layers with $(2 \times 1 \times 3)$ neurons and 1 neuron as output layer. Result and analysis state that average accuracy was $99.25 \%$ in detecting edible and poisonous mushrooms.

Johaira U.Lidasan, Martina P.Tagacay [5] developed a mobile based application to recognize the mushroom using image processing techniques and Neural Network. This method includes image resizing, image segmentation, Feature Extraction, Normalization, Reorganization, classification. Grab Cut algorithm is used to segment mushroom from background, and then mushroom features are extracted. To recognize the mushroom a probabilistic Neural Network is developed, where in the input layer of each neuron is a normalized extracted feature of mushroom image. Then pattern layer is considered which performs dot product between input and weight, divided by a certain bias, so around 665 neurons form 133 training images and 5 features from each image. Finally summation layer is followed by output layer. Resultant accuracy is stated to be $92 \%$

R F Rahmat et.al [6] to classify the poisonous and nonpoisonous mushrooms in a given input images are taken from UCI Machine Learning Repository. Then adopted various image processing stages, 
they are preprocessing with gray scaling image, segmentation with canny edge detection and thresholding, then feature extraction process using zoning method and finally $\mathrm{K}$ nearest Neighbor is used to identify the poisonous mushrooms. A total of 40 mushrooms images were considered with 8 different types.

Ismail, Shuhadia, Amy Rosshaida Zainal, and Aida Mustapha [7] considered Mushroom features like shape, color and surface of the cap, stalk and gill, population and habitat and odour. Principal component analysis (PCA) is used as feature selection by sorting and ranking the attributes. Decision Tree (DT) is a classification algorithm in which each node represents a test of its attributes or features. Waikato Environment for Knowledge Analysis (WEKA) is used for classification experiment. Finally, to test the developed method classification accuracy, coefficient metric and processing times taken are used as evaluation metrics.

Agung Wibowo, Y/uri Rahayu, Andi Riuanto, Taufik Hidayatulloh [8] Applied Algorithms Decision Tree (C4.5), Naïve Bayes, support vector machine (SVM) to identify edible mushroom and their performances are compared. Experiments are carried out in Waikato Environment for Knowledge Analysis (WEKA) environment. Mushroom data of lepiota and agaricus are used to conduct experiment. To evaluate the performance of different algorithms, metrics used are correctly classified instances, incorrectly classified instances, kappa statistic, Mean Absolute Error (MEA), Root Mean Squared Error (RMSE), Relative Absolute Error (RAE), Root Relative Squared Error (RRSE). It is stated that results of the experiment of SVM and $\mathrm{C} 4.5$ algorithm has the same accuracy level, but $\mathrm{C} 4.5$ algorithm has high speed performance compared to SVM.

Lavanya B, G.R. Preethi [9] Applied different decision tree classification algorithms ID3, CART and Hoeffding Tree to classify the edible from poisonous mushrooms. To compare the performance of the different decision tree algorithms, metrics considered are Tree structure, handling missing data, Method of handling attributes selection, time required for the tree construction, error rate, scalability. Compared to ID3 and CART algorithms, Hoeffding Tree algorithm stated as best performer in terms of accuracy and error rate of mushroom dataset.

\section{Comparative Analysis on Different MUSHROOM Classification METHOdS}

After survey conducted on the different available and published papers, this section, presents summary and observation on different classification algorithms developed by the researchers. Authors S.K. Verma, M Dutta (2018), Nusrat Jahan Pinky et.al (2019), Eyad Sameh Alkronz et.al (2019), Ismail et.al (2018), Agung Wibowo (2018), Lavanya B, G.R. Preethi (2017) used mushrooms representing data sets from UCI Machine Learning Repository to classify the edible and poisonous mushrooms using their respective developed data mining algorithms. Above reference papers classify artificially generated mushroom data sets and fixed data sets is considered, so proposed results may or may not work for all practical data sets.

Authors Yasemin Rukiye Erhan, Humar Kahramanli Ornek (2019), Johaira U.Lidasan, Martina P.Tagacay (2018), R F Rahmat et.al (2018) used their own collected mushroom images from different sources to classify the edible and poisonous mushrooms using image processing techniques and different machine learning classifiers. Above references used cropped images of mushroom with small back ground and limited images, so it may serve the few consumers in some situations only. Summarized information is given in Table I.

Table 1. Summary on different mushrooms edibility classification methods

\begin{tabular}{|c|c|c|c|c|}
\hline Reference & Dataset type and size & Technique used & Extracted features & $\begin{array}{l}\text { Observations on } \\
\text { results }\end{array}$ \\
\hline $\begin{array}{l}\text { (S.K. Verma, M } \\
\text { Dutta, 2018) } \\
{[1]}\end{array}$ & $\begin{array}{l}\text { Artificial mushroom } \\
\text { data set of Agaricus } \\
\text { and Lepiota family } \\
\text { from UCI Machine } \\
\text { Learning } \text { Repository } \\
{[10]}\end{array}$ & $\begin{array}{lr}\text { Artificial } & \text { Neural } \\
\text { Networks(ANN) and } \\
\text { Adaptive } \quad \text { Nuero } \\
\text { Fuzzy inference } \\
\text { system } \quad \text { (ANFIS), } \\
\text { Naïve Bayes }\end{array}$ & $\begin{array}{l}\text { Incorrectly classified } \\
\text { instances(ICCI), } \\
\text { correctly classified } \\
\text { instances(CCI), } \\
\text { MAE, Kappa statistic }\end{array}$ & $\begin{array}{l}\text { ANFIS Performance is } \\
\text { better than ANN, Naïve } \\
\text { Bayes. } \\
\text { For ANN algorithm } \\
\text { CCI is } 96.82 \% \text {, MAE is } \\
.033 \text {, Kappa Statistic is } \\
.9316\end{array}$ \\
\hline
\end{tabular}




\begin{tabular}{|c|c|c|c|c|}
\hline & & & & $\begin{array}{l}\text { For ANFIS algorithm } \\
\text { CCI is } 99.75 \%, \text { MAE is } \\
.0018, \text { Kappa Statistic is } \\
.9956, \\
\text { For Naïve Bayes } \\
\text { algorithm } \\
\text { CCI is } 96.817 \% \text {, MAE is } \\
.0333, \text { Kappa Statistic is } \\
.9316 .\end{array}$ \\
\hline $\begin{array}{l}\text { (Nusrat Jahan } \\
\text { Pinky, 2019) } \\
\text { [2] }\end{array}$ & $\begin{array}{l}\text { Dataset consists of } \\
8124 \text { instances and } 22 \\
\text { attributes with } 2 \\
\text { possible class levels } \\
\text { collected from UCI } \\
\text { machine } \\
\text { repository. }\end{array}$ & $\begin{array}{l}\text { Naive Bayes and } \\
\text { dissimilarity } \\
\text { measure, Adboost, } \\
\text { Decision Tree. }\end{array}$ & Accuracy & $\begin{array}{l}\text { Fixed feature set based } \\
\text { models perform better } \\
\text { than randomly selected } \\
\text { set based models }\end{array}$ \\
\hline $\begin{array}{l}\text { (Yasemin } \\
\text { Rukiye Erhan, } \\
\text { et.al, 2019) [3] }\end{array}$ & $\begin{array}{l}\text { Naturally grown } 25 \\
\text { species of mushrooms } \\
\text { at seluck university } \\
\text { campus }\end{array}$ & $\begin{array}{l}\text { Image } \\
\text { processing-threshol } \\
d \text { segmentation, } \\
\text { KNN and Naïve } \\
\text { Bayes }\end{array}$ & Accuracy & $\begin{array}{l}96 \% \text { of accuracy is } \\
\text { achieved by Naïve Bayes } \\
\text { and } 80 \% \text { accuracy by } \\
\text { KNN. }\end{array}$ \\
\hline $\begin{array}{l}\text { (Eyad Sameh } \\
\text { Alkronz et.al } \\
2019)[4]\end{array}$ & $\begin{array}{l}\text { Dataset collected from } \\
\text { UCI machine learning } \\
\text { repository [10] }\end{array}$ & $\begin{array}{l}\text { Multi-Layer ANN } \\
\text { model }\end{array}$ & Accuracy & $\begin{array}{l}99.25 \% \text { of accuracy is } \\
\text { achieved. }\end{array}$ \\
\hline $\begin{array}{lr}\text { (Johaira } & \text { U. } \\
\text { Lidasan, } & \text { et.al } \\
\text { 2018) [5] } & \end{array}$ & 133 mushroom images & $\begin{array}{l}\text { Grab cut for image } \\
\text { segmentation and } \\
\text { Probabilistic Neural } \\
\text { Network for } \\
\text { classification }\end{array}$ & Accuracy & $\begin{array}{l}92 \% \text { of Accuracy rate is } \\
\text { achieved. }\end{array}$ \\
\hline $\begin{array}{l}\text { (R F Rahmat } \\
\text { et.al 2018) [6] }\end{array}$ & $\begin{array}{l}40 \text { mushroom images } \\
\text { with } 8 \text { types amanita } \\
\text { muscaria, floccularia } \\
\text { fusca, galerina } \\
\text { marginata, cortinarius } \\
\text { rubripes, agaricus } \\
\text { bisporus, amanita } \\
\text { phalloides,volvariella } \\
\text { speciosagyromitra } \\
\text { esculenta. } \\
\text { Mushroomserver.org }\end{array}$ & $\begin{array}{l}\text { Canny edge and } \\
\text { thresholding for } \\
\text { segmentation, } \\
\text { zoning method for } \\
\text { feature extraction, } \\
\text { KNN to identify the } \\
\text { poisonous } \\
\text { mushrooms }\end{array}$ & Accuracy & $\begin{array}{l}\text { Average accuracy is } \\
90 \%\end{array}$ \\
\hline $\begin{array}{ll}\text { Ismail } & \text { et.al } \\
\text { 2018) [7] } & \end{array}$ & $\begin{array}{l}\text { Dataset collected from } \\
\text { UCI machine learning } \\
\text { repository [10] }\end{array}$ & $\begin{array}{l}\text { Principal } \\
\text { Component } \\
\text { Analysis (PCA) for } \\
\text { feature selection, } \\
\text { Decision Tree for } \\
\text { classification }\end{array}$ & $\begin{array}{l}\text { Accuracy, Coefficient } \\
\text { Metric and } \\
\text { evaluation time, } \\
\text { Incorrectly classified } \\
\text { instances, correctly } \\
\text { classified instances, } \\
\text { Kappa statistic, } \\
\text { MAE, RMSE, RAE, } \\
\text { RRSE. }\end{array}$ & Claims $100 \%$ accuracy \\
\hline $\begin{array}{l}\text { (Agung } \\
\text { Wibowo et.al } \\
2018)[8]\end{array}$ & $\begin{array}{l}\text { Lepiota and Agaricus } \\
\text { mushroom data set }\end{array}$ & $\begin{array}{l}\text { Decision } \\
\text { Tree(C4.5), Naïve } \\
\text { Bayes, Support } \\
\text { Vector Machine }\end{array}$ & $\begin{array}{l}\text { Incorrectly classified } \\
\text { instances, correctly } \\
\text { classified instances, } \\
\text { Kappa statistic, } \\
\text { MAE, RMSE, RAE, } \\
\text { RRSE }\end{array}$ & $\begin{array}{l}\text { Accuracy levels are } \\
\text { same for SVM and C4.5, } \\
\text { C4.5 is faster than SVM }\end{array}$ \\
\hline
\end{tabular}




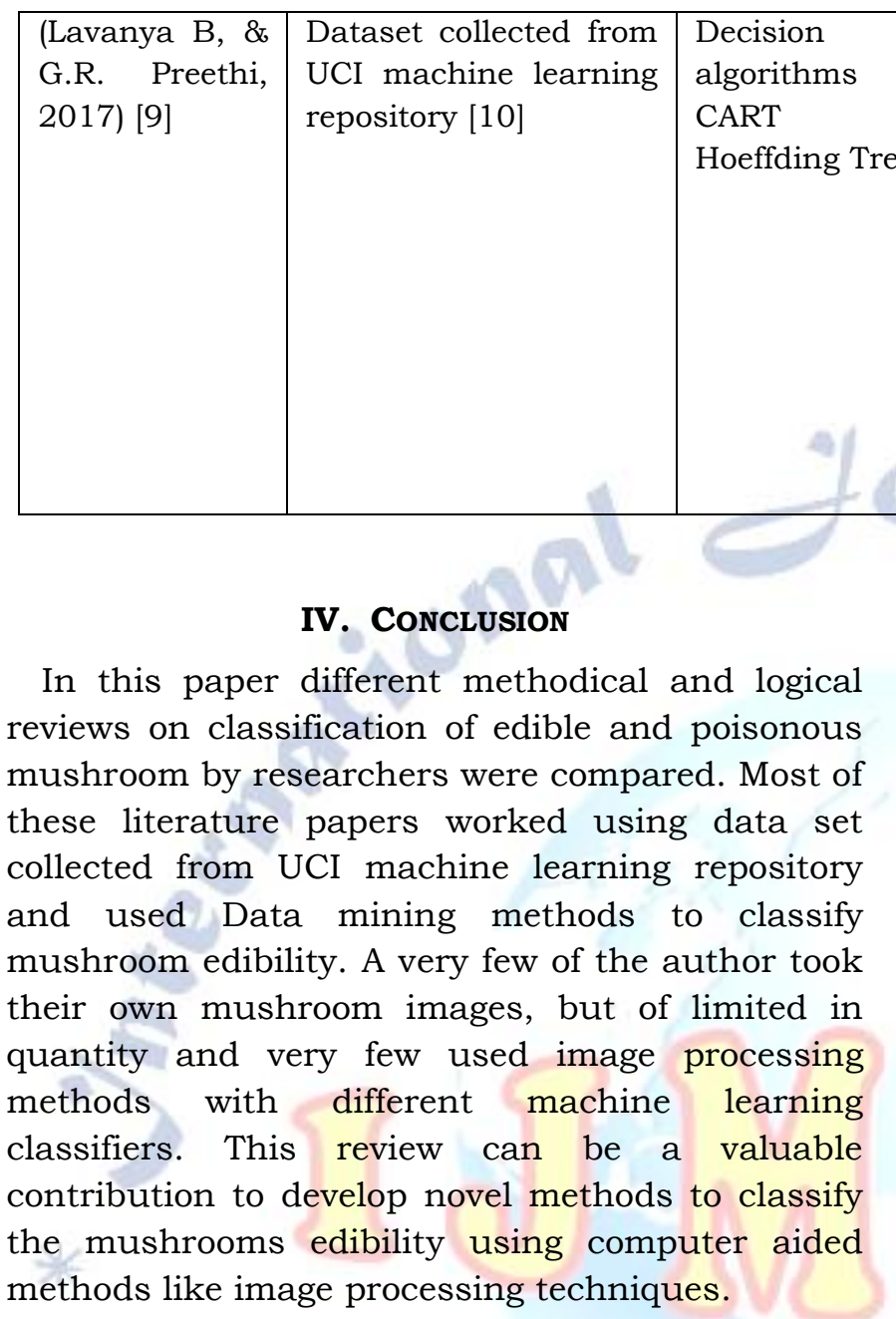

\section{REFERENCES}

[1] S.K.Verma and M.Dutta,"Mushroom classification using ANN and ANFIS algorithm", IOSR Journal of engineering, vol.08, issue 01,2018 , pp. 26-32. Url: http://iosrjen.org/Papers/vol8_issue 1/Version-1/M0801 0194100.pdf

[2] Nusrat Jahan Pinky, S. M.Mohidaul Islam, Rafia Sharmin Alice,"Edibility detection of mushroom using ensemble methods", I.J.Image, Graphics and Signal Processing, vol.04, 2019, pp.55-62. DOI: 10.5815/ijigsp.2019.04.05.

[3] Yasemin Rukiye Erhan, Humar Kahramanli Ornek, "Mushroom Species Detection Using Image Processing Techniques", International Journal of Engineering and Innovation Research, vol.1, issue 2, 2019, pp.71-83 https://dergipark.org.tr/tr/pub/ijeir/issue/50628/5978 07

[4] Eyad Sameh Alkronz, Khaled A, Moghayer, Mohamad Meimeh, Mohannad Gazzaz, Bassem S. Abu-Nasser, Samy S.Abu-Naser, "Predication of whether mushroom is edible or poisonous using Back- Propagation Neural Network", International Journal of Academic and Applied Research, vol.03, issue 02, 2019, pp.1-8.

[5] Johaira U.Lidasan, Martina P.Tagacay, "Mushroom recognition using Neural Network", International Journal of computer Science, vol.15, issue 05, 2018, pp.52-57. http://www.ijcsi.org/papers/IJCSI-15-5-52-57.pdf

[6] R F Rahamat, T Aruan, S Purnamawati, S Faza, T Z Lini, Onrizal,"Fungus Image Identification using K-Nearest Neighbor", 2nd Nommensen international conference in technology and engineering, IOP Conf. Series: materials

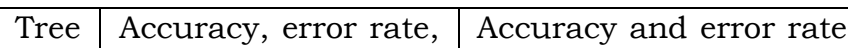

ID3, Tree structure, with Hoeffding Tree

and Handling missing algorithm is best

data, Method of compared with ID3 and handling attributes CART

selection, time

required for the tree

construction error

rate, Scalability

Science and Engineering vol.420, 2018, pp.01-07. https://iopscience.iop.org/article/10.1088/1757-899X/4 $20 / 1 / 012097 / \mathrm{pdf}$

[7] Ismail, Shuhadia, Amy Rosshaida Zainal, and Aida Mustapha, "Behavioral Features for mushroom classification", IEEE Symposium on computer Applications \& Industrial Electronics, 2018, pp.412-415. DOI: 10.1109/ISCAIE.2018.8405508, https://ieeexplore.ieee.org/document/8405508

[8] Agung Wibowo, Y/uri Rahayu, Andi Riuanto, Taufik Hidayatulloh,"Classification Algorithm for Edible Mushroom Identification", International Conference on Information and Communications Technology, 2018, pp.250-253.Doi: 10.1109/icoiact.2018.8350746, https://ieeexplore.ieee.org/document/8350746.

[9] Lavanya B, G.R.Preethi, "Performace Analysis of Decision Tree Algorithms on Mushroom Dataset", International Journal for Research in Applied Science and Engineering Technology, vol.5, issue 11,2017 , pp.183-191. https:/ / ijraset.com/fileserve.php?FID=10826.

[10] K Bache, M. Lichman, "UCI Machine Learning Respository", Available online: http:// archive.ics.uci.edu/ml. 